\title{
Ciencias sociales, mundo y pandemia: por un futuro posible
}

\author{
José Miguel Segura-Gutiérrez \\ Magister en Desarrollo Educativo y Social. Administrador Público \\ Universidad Cooperativa de Colombia. Villavicencio, Colombia \\ https:/ / orcid.org/0000-0001-6679-5895• jose.segurag@campusucc.edu.co
}

\section{Lina Paola Vásquez-Ávila}

Magister en Administración. Administradora de empresas

Universidad Cooperativa de Colombia. Villavicencio, Colombia

https:/ / orcid.org/0000-0002-1388-5915 • lina.vasqueza@campusucc.edu.co

\section{Resumen}

La reflexión expuesta en el documento aborda las ciencias sociales, en una perspectiva compleja y multidimensional, cuyo propósito es atender a los retos coyunturales y futuros derivados de la pandemia del COVID-19, en tanto instrumento reconfigurador de un nuevo orden mundial. Por tal motivo, el análisis mostrará el panorama que esbozan las ciencias sociales ante la coyuntura actual, y planteará algunas líneas de reflexión frente al futuro posible de la humanidad y de la institucionalidad ante el nuevo escenario social. Esto a partir de un ejercicio de revisión bibliográfica, que visibiliza la profusa reflexión frente a la construcción de las ciencias sociales del futuro.

Palabras clave: Pandemia COVID-19; Mundo; Ciencias sociales; Futuro.

Recibido: 23/03/2021| Aprobado: 18/08/2021 | Publicado: 01/01/2022

(c) (1) (2) Esta obra está bajo una Licencia Creative Commons Atribución-NoComercial- 


\title{
Social Sciences, the World and the Pandemic: for a Possible Future
}

\begin{abstract}
The reflection presented in the document addresses the social sciences, from a complex and multidimensional perspective, whose purpose is to address the current and future challenges derived from the COVID-19 pandemic, as a reconfiguring instrument of a new world order. The analysis will show the panorama outlined by the social sciences in the current situation, and will propose some lines of reflection regarding the possible future of humanity and institutions in the face of the new social scenario. This is based on a bibliographic review, which makes evident the profuse reflection on the construction of the social sciences of the future.
\end{abstract}

Keywords: COVID-19 pandemic; World; Social sciences; Future.

Sumario: 1. Introducción, 2. Reflexión teórico-conceptual, 2.1 Ciencias sociales: un globo que se parte de la tierra y ve hacia ella, 2.2 Nuevo orden mundial: asomos y nuevas coaliciones, 2.3 El futuro posible: una reflexión frente a la vida, 3. Conclusiones, 4 . Referencias bibliográficas. 


\section{Introducción}

Debido a los acontecimientos a nivel mundial suscitados por la propagación del COVID-191', el mundo cierra el año 2020 en medio de una gran convulsión social, política, económica y cultural. La pandemia ha generado gran efecto negativo en las economías de América Latina. Según la Comisión Económica para América Latina y el Caribe (CEPAL, 2020) se produjo una reducción del PIB en menos 7.7\% en América Latina y en América del Sur en un menos $7.3 \%$, esto significa un crecimiento de la pobreza y la desigualdad. Además, un retroceso en el sector turístico de la región (Ver Tabla 1). Por tanto, ha favorecido la resignificación del papel de las ciencias sociales, en tanto conjunto de disciplinas que estudian fenómenos relacionados con la realidad compleja, variable y diversa del ser humano.

Tabla 1. América Latina (20 países variación proyectada del PIB, 2020 (En porcentajes)

\begin{tabular}{cccc}
\hline País & Variación del PIB & País & Variación del PIB \\
\hline Argentina & -11.5 & Costa Rica & -4.8 \\
Bolivia (estado Plurinacional) & -8.0 & Cuba & -8.5 \\
Brasil & -5.2 & El Salvador & -8.6 \\
Chile & -5.9 & Guatemala & -2.5 \\
Colombia & -7.1 & Haití & -3.0 \\
Ecuador & -9.0 & Honduras & -8.0 \\
Paraguay & -1.6 & México & -9.0 \\
Perú & -13.4 & Nicaragua & -5.5 \\
Uruguay & -4.5 & Panamá & -11.0 \\
Venezuela (República Bolivariana) & -28.0 & República Dominicana & -5.5 \\
América del Sur & -7.3 & Centroamérica y & -8.5 \\
& & México & -6.6 \\
& & Centroamérica & -7.7 \\
\hline
\end{tabular}

Fuente: CEPAL, 2020.

A partir del surgimiento de la enfermedad, y de las medidas adoptadas por diferentes gobiernos del mundo para frenar su propagación, se trastocaron de forma tangible las dinámicas de las distintas sociedades y regiones. Revelando así, no solo nuevas problemáticas socioeconómicas sino también problemáticas sociales preexistentes (desigualdad, exclusión, estigma). Por consiguiente, la pandemia, las medidas de contención y prevención social de emergencia para frenar la pobreza y la pobreza extrema

1 La abreviatura denota “CO” para corona, “VI" para virus, “D” enfermedad y "19" como el año en que la enfermedad se hizo visible por primera vez. El virus que causa la COVID-19 ha sido nombrado SARS-CoV2 y está dentro de los virus que causan el "síndrome respiratorio agudo severo". 
Segura-Gutiérrez y Vásquez-Ávila

no fueron suficientes, la mayoría de los países tuvieron un deterioro distributivo en el ingreso per cápita. En el año 2020, se presentó un aumento de la tasa de la pobreza extrema en un $12,5 \%$ y la situación de pobreza estaría en un 33,7\% (Ver Figura 1). Así mismo, se observa una reducción de los ingresos laborales, movilidad descendente en los estratos de ingresos medio a medio bajo. Que, sin duda justifican el indagar acerca de los desafíos que enfrenta el mundo ante la emergencia sanitaria, además de explorar algunas tendencias que orienten la comprensión de sus dinámicas futuras desde el campo de las ciencias sociales.

Figura 1. América Latina (18 países) a: población según estratos de ingreso per cápita, 2019 y 2020 (En porcentajes).

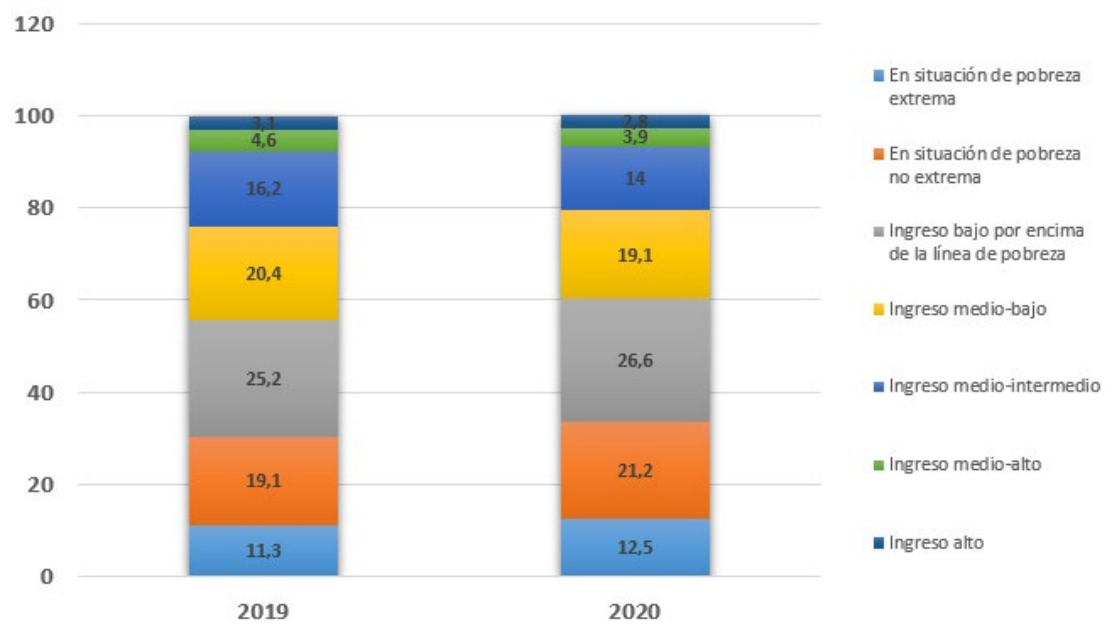

Fuente: Comisión Económica para América Latina y el Caribe (CEPAL), sobre la base de Banco de Datos de Encuestas de Hogares (BADEHOG) ${ }^{2}$.

Pensar la pandemia COVID-19 desde las ciencias sociales y en clave de futuro, significa reflexionar sobre los retos coyunturales y futuros que afrontarán las relaciones humano-sociales, políticas y económicas con ocasión de la crisis sanitaria, pero sin desconocer que sus raíces se hunden en temas más estructurales y que requieren de un acercamiento crítico y ético ante este riesgo global, hoy convertido en una amenaza concreta para las personas, poblaciones y ecosistemas del mundo.

Según cifras del Centro de Ciencias e Ingeniería de Sistemas (CSSE, 2021) de la Universidad Johns Hopkins, son 241 millones de personas infectadas por SARS-CoV-2 y 4.908.879 muertos registrados en todo el mundo. Además de las consecuencias de la

2 Cifras ajustadas a perspectivas de población mundial, versión 2019, y estimaciones de evolución de la pobreza de países cuyas mediciones no están disponibles para los años indicados. Los países incluidos son: Argentina, Bolivia (Estado Plurinacional de), Brasil, Chile, Colombia, Costa Rica, Ecuador, El Salvador, Guatemala, Honduras, México, Nicaragua, Panamá, Paraguay, Perú, República Dominicana, Uruguay y Venezuela (República Bolivariana de). 
pandemia y otros factores sociopolíticos y económicos, según la CEPAL (2020) se estima que un total de 209 millones de personas pobres ascendería al terminar el año 2020, esto significa 22 millones personas más que el año anterior. (Ver Figura 2 y 3). Panorama que contrasta con la descripción poética que realiza Barba-Jacob (2011) en Canción de la vida profunda cuando con cierta musicalidad vocal expone en unos de sus versos que "Hay días en que somos tan móviles, tan móviles, como las leves briznas al viento y al azar... Tal vez bajo otro cielo la Gloria nos sonría... La vida es clara, undívaga, y abierta como un mar...".

Figura 2. Total casos de personas infectadas por SARS-CoV mundo y Colombia-octubre 2021.

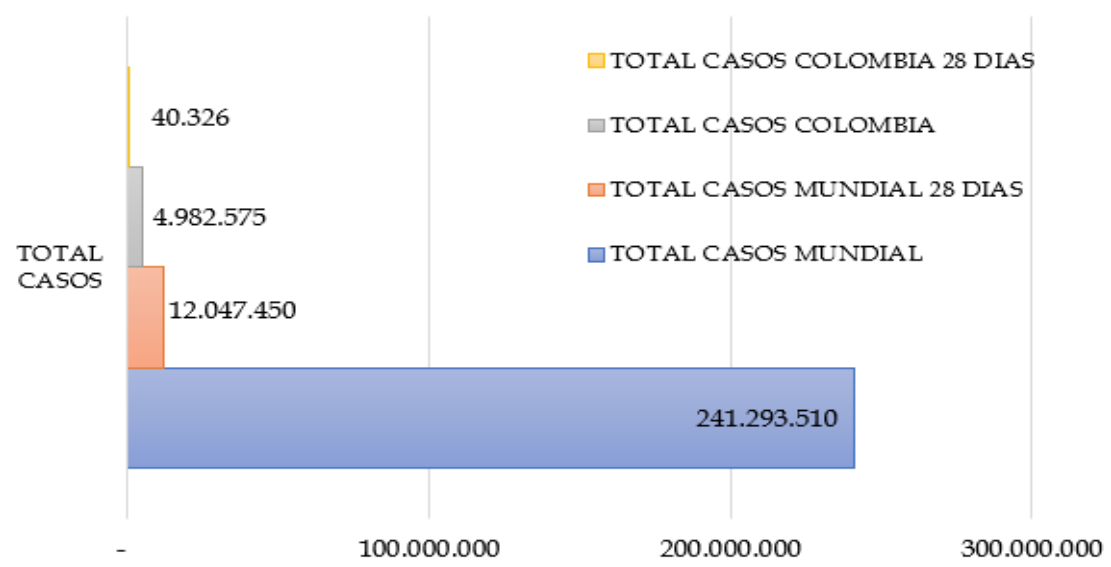

Fuente: CSSE, 2021 de la Universidad Johns Hopkins

Figura 3. Total casos de personas muertas por SARS-CoV mundo y Colombia - octubre 2021.

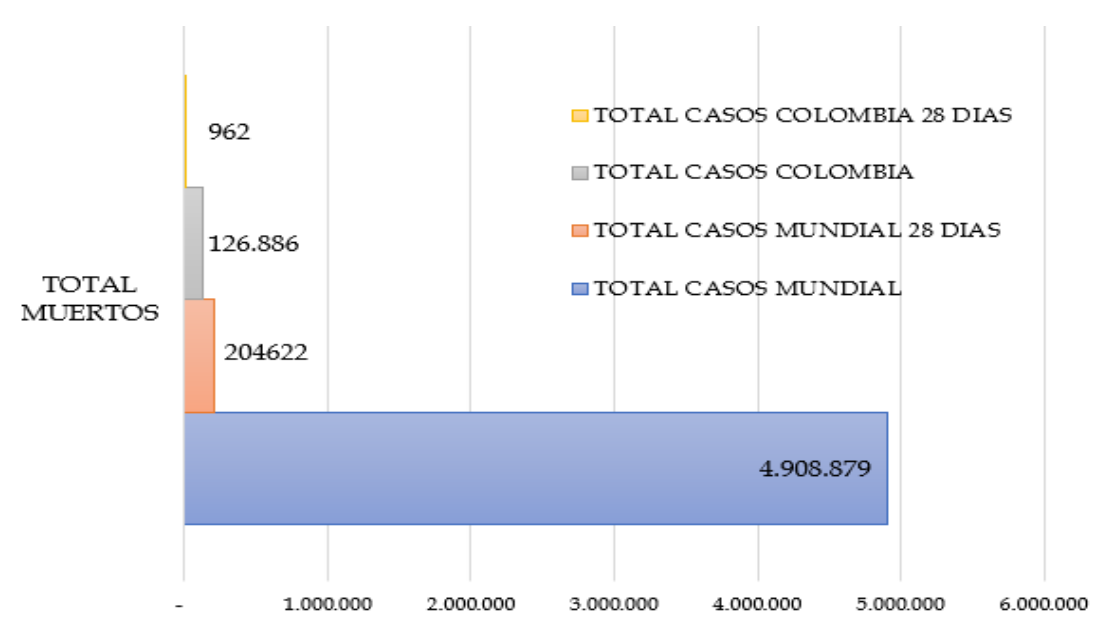

Fuente: CSSE, 2021 de la Universidad Johns Hopkins. 


\title{
2. Reflexión teórico-conceptual
}

\subsection{Ciencias sociales: Un globo que parte de la tierra viendo hacia ella}

\author{
Voy a salir \\ Aquí no puedo respirar \\ Sellé ventanas para dejar de sentir \\ $Y$ ahora no siento más que astenia emocional \\ Quiero descomprimir \\ Volver a ver con claridad \\ Tomar las alas como Reichelt en París \\ $Y$ planear y ser aurora boreal \\ $Y$ resurgir, y levitar, y sentir al fin, la antigravedad
}

(La Casa Azul, 2018).

La capacidad crítica de las ciencias sociales para leer los cambios históricos, sociales, políticos, culturales y, por qué no, ambientales, generados por el COVID19 durante el periodo de aislamiento social y de pospandemia, ponen de manifiesto no solo la ruptura de las sociabilidades, la generación de miedo y el señalamiento de distintos lugares y diferentes poblaciones como de riesgo, sino también la necesidad misma de pensar desde la coyuntura actual y el conocimiento científico social acumulado, herramientas que le permitan al ciudadano leer la infodemia que se está viviendo, y sacar conjeturas acerca de sus efectos. Tal como lo hiciera un chico que por primera vez toma en sus manos un globo, con el deseo que éste pronto alce a volar.

\footnotetext{
Aunque cada una de las ciencias sociales haya tenido procedencias distintas como la guerra, la pobreza, la religión, los viajes, la locura, lo cierto es que todas pasaron por la escuela, y en esta última se produjo un saber que haría parte indiscutible del conjunto de categorías que aleatoriamente han ido tributando a un corpus teórico que no cesa de cambiar. (Álvarez-Gallego, 2014, p. 46)
}

Situación que sugiere la identificación de un lugar común frente a su acceso (escuela), además de revelar niveles diferenciales de desarrollo en cada una de las disciplinas que integran este campo de conocimiento, y que, como producto del periodo de posguerra fría, hizo exigente la incorporación de criterios tecno-científicos en la configuración del nuevo orden mundial que se esbozaba y traería consigo la tecnocracia y el capitalismo en tanto ejes articuladores de la nueva dinámica gubernamental y económica, en que se encarrilarían el mundo y la academia; esta última, en lo que refiere a las formas de producción académica, y sus efectos específicos en las ciencias sociales en América Latina, en donde, según Carli (2014): 
[...] a partir de los años noventa, las ciencias sociales sufren cambios en sus contenidos y formas con el despliegue de la profesión académica, el desarrollo de nuevos enfoques y paradigmas teóricos y la emergencia de problemáticas regionales en un ciclo con tendencias neoliberales y posneoliberales en el que los intercambios regionales e internacionales se han intensificado. (p.

66)

Ante este panorama, las ciencias sociales tuvieron que desarrollar cierto nivel de competencia o capacidad para internacionalizar los asuntos domésticos, reconociendo para ello, sus particularidades históricas, pero también, interviniendo en los círculos mundiales de producción de conocimiento (teorías, herramientas de investigación y modelos de acción política). Como se sabe, el derrotero de las ciencias sociales siempre ha estado atravesado por problemáticas y acontecimientos de la realidad social y política que han intervenido en su configuración, a tal punto que hoy se reclama como imperativo en el análisis social, no desagregar y trabajar por procesos. Esto en el entendido que las nuevas dinámicas mundiales hacen cada vez más visible la articulación entre conocimiento y realidad, y son las ciencias sociales con sus disciplinas, las encargadas de explorar tales relaciones desde el pasado reciente, el tiempo presente y el futuro.

En palabras de Brown (2002):

La ciencia social es en la actualidad una forma de comunicación pública que no sólo cobra importancia dentro de las universidades, sino que también lo hace en las actividades cotidianas de todos los miembros de la sociedad. Al ser vista como un discurso cívico, es decir, un lenguaje compartido a través del cual los individuos logran conocerse a sí mismos y moldear su mundo, la ciencia puede ayudar a construir una sociedad más justa y democrática, una economía más sostenible, y una vida personal más provechosa. Hoy en día, la ciencia, especialmente la ciencia social, es un modo de acción ética y política. (p. 27)

Por tal motivo es que nos, interesamos en señalar desde las ciencias sociales algunas de las vulnerabilidades sociales, ambientales, sanitarias e institucionales, que ha generado la pandemia del COVID-19, y que permitan identificar la agudización, al menos en América Latina, de los escenarios de pobreza y marginación social que sufren ciertos grupos por cuestiones raciales (Devakumar, Shannon, Bhopal \& Abubaka, 2020). Esto sin dejar de mencionar el incremento de la violencia de género en contra de las mujeres (Mazza, Marano, Lai, Janiri \& Sani 2020) y en contra de la comunidad LGTBIQ+ (Fuchs \& Potter, 2020). Fenómenos sociales, inscritos dentro del modelo económico de corte neoliberal, y que pese a los cercos sanitarios y declaratoria de cuarentenas obligatorias por parte de diferentes gobiernos del mundo, no ha detenido la demanda de recursos minero-energéticos, el azuzamiento del consumo no responsable, así como la ejecución de prácticas comerciales con altos sobrecostos en lo que respecta a compras de elementos de higiene y alimentos básicos por parte de administraciones locales para atender la crisis. 
Escenario que lleva a que la investigación social deba innovar frente a la forma como plantea las preguntas que han de dar cuenta de la complejidad de la reproducción social y de las concatenaciones que el ser humano establece con la naturaleza (Covarrubias-Villa y Cruz-Navarro, 2019). Pero, ante todo, de reconocer que el virus o agente patógeno COVID19 ha coincidido históricamente con la crisis del neoliberalismo (Ruiz y Caviedes, 2020), y que los paradigmas científicos e ideologías desarrollados en el marco de esta política de acumulación de capital deban superarse dada su caducidad histórica (Catanzaro, 2019); para dar paso ahora al establecimiento de una nueva relación entre Estado, academia y sociedad, cuyo eje será el trabajo colaborativo en pro de la construcción de medidas menos coercitivas, de persecución y castigo frente al manejo de situaciones de riesgo como la provocada por el COVID-19.

Sin duda, las ciencias sociales metafóricamente pueden explicarse como un globo que parte de la tierra viendo hacia ella, para así no perder de vista la realidad del objeto de su estudio y de esta manera posibilitar la entrega de respuestas viables, de acuerdo con una gramática disciplinar propia, que no riñe con la subjetividad del investigador en tanto sujeto sentipensante dentro de la complejidad social que caracteriza estos tiempos. Según la teoría luhmanniana de la diferenciación funcional, se considera a la sociedad como una entidad plenamente mundializada. Sin embargo, su actual conformación admite diferenciaciones internas, que a su vez definen sistemas sociales especializados, en donde "cada sistema 194 funcional está diferenciado para cumplir una función específica” (Luhmann, 2007, p. 591). Cuestión que explicaría por qué los actuales retos impuestos por la pandemia no hayan podido resolverse con decisiones unitarias.

En efecto, las perspectivas hasta ahora proyectadas para interpretar "los hechos", recomendar "las acciones" y decidir "las medidas", dejan ver cómo "la diferenciación funcional -como forma de diferenciación de la sociedad- enfatiza la desigualdad de los sistemas de función" (Luhmann, 2007, p. 591). Tanto que en algunos casos son las combinaciones de asuntos políticos, económicos y jurídicos las que prevalecen. No obstante, dado el tono cambiante que imprime la propagación del virus COVID-19, éstas se modifican de forma dinámica incluyendo nuevos asuntos. Razón por la cual, se hace necesario entender que, dada las dimensiones alcanzadas por la pandemia, corresponda a las organizaciones en tanto actores colectivos gestionar las acciones para remediar la crisis sanitaria producida por la COVID-19.

Según lo advierte Luhmann (2007), "las organizaciones son los únicos sistemas sociales que pueden comunicarse con su entorno" (p.668). Incluso, cuando éstas también se guían por propósitos diversos (económicos, humanitarios, políticos e ideológicos), pero que en últimas buscan reducir el impacto social de la pandemia del COVID-19, y contribuir en la ampliación de los diferentes campos de estudio en que se encauzan las ciencias sociales. Las ciencias sociales proporcionan una base de conocimiento desde la cual las personas 
puedan entender el mundo en sociedad, además de jugar un papel importante en el análisis de las diversas manifestaciones que ha adquirido esta crisis pandémica, como también, de las distintas formas de actuación colectiva que se puedan adoptar para mitigar sus efectos (Fernández-Esquinas, 2020).

La actual crisis se ha convertido en un desafío institucional amplio que requiere de las herramientas de análisis de las ciencias sociales para vislumbrar los impactos sociales, económicos, políticos y culturales derivados de tales intervenciones institucionales, pero reconociendo el papel que la gestión de la información científica tiene en la proyección de soluciones razonables. En su prólogo, Álvaro Díaz Gómez describe cómo una expresión local, a saber el COVID-19, se ha diseminado por un número significativo de países a nivel global dejando millones de personas infectadas y otras tantas muertas, pero también, revelando campos de interés para las ciencias sociales como la globalización, los individualismos, la biopolítica, el neoliberalismo, la ciudadanía, que sin duda hacen imperativo reflexionar en torno a nuestras prácticas sociales, formas de expresión, y conceptualización del cuidado, dentro de coordenadas histórico-culturales precisas, y que aporten a la producción de conocimiento para afrontar esta realidad (Flores-Osorio, HuertaCharles y Bravo, 2020).

Con sano criterio, ha sido gracias a las ciencias sociales y su interés por reflexionar sobre el poshumanismo, la incertidumbre ante el uso de los recursos naturales, el desarrollo de las sociedades y lo indeterminado de la planeación del futuro tecnológicocomputacional, con sus posibilidades de lo diverso, complejo y simultáneo de la información, que el futuro mismo de este campo del saber ha generado nuevas teorías, conceptos y proyectado mundos posibles no lineales, para que los cambios y transformaciones a las situaciones de vida y aprendizaje social pospandémico, puedan avizorar un horizonte de esperanza, sobre el devenir político y social del mundo. "El reto para las ciencias sociales se advierte, entonces, disruptivo y no lineal, pues los procesos socioculturales que se vienen gestando, además de ser exponenciales, requieren de una constante innovación conceptual" (Barreneche-Jurado et al., 2018, p. 171), que permita, dar cuenta de una situación que no se vivía a escala global desde hace unos cien años, y que dentro del actual marco de desarrollo tecnológico y comunicacional resulta por completo incierta y novedosa, pero a su vez, beneficiaria de la reflexión no solo contextual, sino de mediano y largo plazo.

Lo que pueden hacer las ciencias sociales para aportar a la reflexión sobre la pandemia del COVID-19 y la generación de planes de acción efectivos, es reconocer, en primera instancia, la vigencia de la sentencia socrática de "que solo sé que no sé nada", para así, ratificar la existencia de fronteras del conocimiento, y definir nuevas líneas de investigación frente a esta experiencia que no solo tiene efectos sobre la salud humana y animal, sino sobre el conjunto de relaciones sociales (familiares, de género, ámbito escolar o educativo), 
políticas, culturales, económicas (desigualdad), y que exige de un abordaje interdisciplinar cuya intención ético-moral consiste en problematizar las situaciones, analizar sus interrelaciones y recomendar un camino de solución razonable, a compartir con los agentes públicos o tomadores de decisiones.

La dimensión que la pandemia tiene y proyecta, lo que ha vislumbrado es un alto grado de incertidumbre sobre cómo se desarrollará esta situación y de qué manera afectará las interacciones humanas, sociales, comunitarias e institucionales (estatales o políticas). Tanto así, que uno de los efectos inmediatos de esta pandemia ha sido el retorno a la centralidad del Estado en tanto detentador del poder supremo, y de los gobiernos como mecanismos de gestión administrativa de la confianza de los ciudadanos ante las respuestas que se vienen proyectando para salir de la crisis, y en donde las instituciones como proveedoras de servicios públicos tienen una responsabilidad importante, en lo que refiere a las visiones de futuro que se ofrecerán para la sociedad global, a partir de la toma de decisiones políticas que afectarán los antiguos acuerdos sociales, escenarios de participación y forma en que trascurrirá la vida en el futuro.

Según lo consignado en el prólogo de Sara Victoria Alvarado, el asedio al que se enfrenta el desarrollo de las ciencias sociales en América Latina, ante la radicalización del autoritarismo como producto de la naturalización de las políticas de corte neoliberal, expone graves efectos para los ecosistemas, vínculos comunitarios y dinámicas propias de los territorios de esta región y de la diversidad natural y cultural del mundo (Rodríguez-Basail, 2019). Tanto que el papel a cumplir por parte de las ciencias sociales en su intención de describir las causas de esta coyuntura y de lo que vendrá después de lo sucedido (ruptura de la normalidad), deba orientarse hacia la reflexión sobre la cuarentena mundial, la aceleración de los efectos que el capitalismo ha tenido sobre los ecosistemas y las poblaciones, así como la construcción de un nuevo orden mundial. "Históricamente, las pandemias han obligado a los seres humanos a romper con el pasado e imaginar su mundo de nuevo. Esta no es diferente. Es un portal, una puerta entre un mundo y el siguiente" (Roy, 2020).

Un puente (Feige \& Branagh, 2011) bifrost $^{3}$, cuyo poder reside en su capacidad para aniquilar otros mundos, si no se gestiona de manera responsable, y bajo la guía de preceptos como el trabajo comunitario y político del autocuidado, en tanto ejes claves de acción para responder a la pandemia y al miedo que genera este virus, y logra liberar otros desastres, en parte ocasionados por la dinámica neoliberal, bajo su consigna de mercantilizar la naturaleza, hacer del sujeto humano un empresario de sí mismo y desmontar de forma progresiva y sin resistencias, los sistemas de protección social. El valor del capital dentro del plano neoliberal se mueve bajo el horizonte de la trasformación del paisaje y de la vida,

3 Sugiero la analogía de acuerdo con la de "Thor" de Marvel. 
el incremento de la productividad y el desarrollo del mercado de consumo, como producto de la globalización.

\title{
2.2 Nuevo orden mundial: asomos y nuevas coaliciones
}

\author{
Va a costar \\ Hacer cuenta que no hay dolor \\ Que todo sigue igual \\ Esconder los desperfectos y disimular \\ Qué bonita es la felicidad \\ Podría ser peor \\ Nuestra frase favorita del despertador. \\ El recurso eterno socorrido y sanador \\ Déjame gritar \\ (La Casa Azul, 2016).
}

A la fecha -y como producto de la pandemia del COVID-19- la mirada del mundo desarrollado y no desarrollado, y en especial de sus equipos de investigación científica, se halla dirigida a la consolidación de una potencial vacuna o tratamiento contra la enfermedad que este virus desarrolla, situación que ha requerido por parte de sus líderes el diseño de estrategias (protocolos en el desarrollo de actividades comunes y específicas, cuarentenas localizadas, alternancia en el desarrollo de actividades productivas y medidas de pico y cédula para circular por las ciudades), que permitan controlar la dispersión del SARS-CoV-2, reducir el número de contagios y mantener así la disponibilidad de las Unidades de Cuidados Intensivos libres ante cualquier incremento en el número de afectados por este virus.

Una panorámica que sin duda también concentra la atención de las ciencias sociales, ante las problemáticas sociales, culturales, políticas y económicas generadas por esta coyuntura. La situación generada por la emergencia mundial ha obligado a que los gobiernos se acerquen a la academia para buscar alianzas que permitan generar acciones activas para mitigar las consecuencias de dicha pandemia sobre la salud de la población y la economía. En especial frente a cómo asegurar los ingresos de las familias y el moderar el impacto del gasto público.

Todos los países, más allá del espectro político y de la aprobación del gobierno, de su momento económico, y de cualquier otra caracterización posible, han tenido que atender una emergencia humanitaria en medio de una crisis global cuyo par más cercano ocurrió hace más de cien años. La economía global, una tecnología intangible y planetaria, se encuentra en jaque por un agente infeccioso tan pequeño que no es considerado vivo en un sentido estricto. (Isaza-Villamizar et al., 2020, p. 4) 
Cuestión que requiere identificar algunos fenómenos que ya venían presentándose en el contexto de los países desarrollados como el lento crecimiento y aumento de la especulación, y que con la pandemia se visibilizaron las crisis internas y configuraciones del poder hegemónico, mientras que del lado de los países no desarrollados, estos se vieron afectados en lo que concierne a los procesos de integración comercial, como producto de la inestabilidad cambiaria y restricciones al tráfico de mercancías (importación/exportación). Esto sin descontar los efectos negativos sobre la producción nacional y el empleo, pero no así sobre la disponibilidad del dinero circulante y la masificación de la digitalización como recurso de inclusión financiera. Al hacer uso de la tecnología en las transacciones bancarias, se ofrece mayor seguridad para los clientes ante el contexto actual de emergencia sanitaria.

Es por tal motivo que discutir en torno a la reconfiguración de un nuevo orden mundial, requiera de describir el sistema capitalista actual, entendido como un sistema social, que acentúa la concentración de la riqueza en pocas manos, favorece el deterioro ambiental, y acrecienta la práctica individualista y de meritocracia. Desde el inicio de la pandemia generada por el COVID-19, las falencias del modelo, así como del deterioro del sistema social (salud, educación y pensional), político y económico a nivel mundial no se han hecho esperar. Mostrando cómo esta situación "es sin duda el comienzo de una nueva era: el mundo nunca será el mismo" (Kissinger, 2020). Y las ciencias sociales, tendrán un nuevo elemento para investigar en su agenda.

Como producto de la crisis sanitaria mundial, las directrices de gobierno en diferentes países se han orientado al distanciamiento social, cierres de escuelas, cierre de negocios; decisiones administrativas y en ocasiones políticas cuyas consecuencias más inmediatas se ven reflejadas en el desempleo, la incertidumbre económica, la reducción de los ingresos, el aumento de la pobreza y las desigualdades. Esto sin dejar de lado las falencias en los sistemas de salud, ante la dificultad de realizar testeos al grueso de la población más vulnerable al virus $y$ de aquellos que se encuentran confinados en centros de disciplinamiento social y de cuidado en salud.

Lo que evidencia que, pese a que antes del COVID-19 el mundo se hallaba integrado en una economía mundial globalizada en regiones, y en donde las primeras manifestaciones de cooperación regional fueron agenciadas por Europa y Latinoamérica para la década del 40, los efectos de la pandemia han dejado ver hoy cómo el regionalismo mundial lo que ha hecho es formalizar el desarrollo de relaciones y acuerdos entre países, asegurando así un espacio para la gobernanza plural o global, pero no protegiendo a las personas que integran cada país pertenecientes a estos bloques.

Ante la pandemia los diferentes gobiernos, se hallan más orientados hacia la protección de sus economías internas para generar crecimiento y prosperidad económica, que, en preservar la salud de sus pobladores, principalmente los adultos mayores y la 
población vulnerable (pobres). De manera particular, en Latinoamérica la pandemia evidenció una falta de coordinación y consenso entre los estados de la región, a tal punto que Pignatta (2020) genera cuatro coyunturas críticas: la primera, los ámbitos multilaterales como UNASUR, MERCOSUR, OEA descoordinados en directrices grupales para la contención de la pandemia; la segunda, la suspensión de elecciones generó protestas; la tercera, la necesidad de respuestas a las desigualdades sociales y económicas quedaron expuestas en la pandemia; por último, crisis y agendas, esto priorizó el sistema de salud, educación, ambiental la investigación científica, seguridad alimentaria.

Por tanto, la dificultad ha permitido que algunos gobiernos revisen sus políticas de bien común y tomen medidas para proteger a su población, además de valorar su papel como agentes que operan bajo los principios de equidad, solidaridad e igualdad, contribuyendo al bienestar social de sus pobladores. De acuerdo con Smouts (1997), los bloques económicos contienen cooperación y apoyo al desarrollo, también los intercambios económicos, inversiones en fortalecimiento institucional, defensa de derechos humanos, desarrollo sostenible, condiciones de trabajo, inclusión social, recursos energéticos, seguridad y acciones contra la pobreza y flujos ilegales e ilegítimos.

Razón para preguntar por ¿Cuáles serán los cambios o tendencias después de la pandemia en el contexto? Respuesta que desde Busso (2020), se ancla a la idea gramsciana que lo viejo no quiere morir, y para lo cual ofrece un listado de lo viejo que no quiere morir, $\mathrm{y}$ en donde destaca el sector financiero transnacional, las empresas beneficiadas por el consumo de la pandemia (bancos, empresas de venta online, empresas de domicilio, empresas de consumo, laboratorios de la posible vacuna). Todo lo cual evidencia el aumento de la pobreza y recesión económica y también la perdurabilidad de los gobiernos de corte neoliberal o extrema derecha.

Sin duda, con la propagación del virus y su potencial riesgo para la salud de buena parte de la población, el mundo aparece hoy a los ojos de las personas como descentrado, siendo la única realidad posible la digital. Situación que supone una interdependencia recíproca entre los gobiernos del mundo, pero también, una nueva base para el fortalecimiento de los procesos de integración comercial a nivel global y ante problemáticas como el calentamiento global. Ahora ya no son guiados por un solo vector ubicado en el hemisferio norte, sino, por otros actores que se trepan al cuadrilátero de la competencia internacional, buscando desestabilizar su poder, lo cual, en palabras de Martz-Fernández (2017), deja ver cómo las transiciones políticas por regla general se identifican por la pérdida de hegemonía de un actor de poder o, de un conjunto de actores de poder, para dar paso a otros cuyas ideologías e intereses estratégicos, afectarán la vida en sociedad y, por extensión, las relaciones en el sistema-mundo. Algo similar a lo que ocurre con los clanes de leones en las sábanas africanas, cuando se enfrentan a otros clanes por su territorio y lo que obtienen es acecho, sangre y muerte. 
El nuevo orden mundial, establecido por causa de la pandemia hoy se lee desde las reformas institucionales que agencian los países en aras de contrarrestar los efectos del virus, reactivar la economía, pero olvidando un ejercicio claro de consulta o diálogo con las comunidades en tanto detentadoras del poder primario y beneficiarias de las decisiones que toman quienes fungen como sus representantes en los diferentes cuerpos políticos decisionales. Razón por la cual, el nuevo orden mundial, se asoma como un escenario de discusión frente a la responsabilidad sobre el origen y antecedentes de la pandemia de COVID-19, para luego, examinar las acciones gubernamentales de tipo global y local, que serán fortalecidas y darán lugar a una recuperación gradual y, esperamos guiada por una nueva directriz, esta vez, más cercana a nosotros, es decir más humana, social y en diálogo permanente con la naturaleza. En la actualidad estamos frente a iniciativas sin conexión entre lo que desea la nación, cuál es el papel del Estado y qué medidas se deben tomar a nivel ético y político para cuidar el ambiente en tanto posibilitador la preservación de la humanidad.

\subsection{El futuro posible: una reflexión frente a la vida}

¿Quién eres? ¿Por qué me sigues tan de cerca y sin hacer ruido? (Pato)
La muerte le contestó:
Me alegro que por fin me hayas visto.
Soy la muerte.
El pato se asustó.
Quién no, le habría hecho.
¿Ya vienes a buscarme?
He estado cerca de ti desde el día en que naciste...por si acaso

(Erlbruch, 2007).

Hablar del futuro, dentro del contexto actual de la pandemia del COVID-19, significa desafiar el miedo a pensar de forma distinta a la que la vida cotidiana nos ha tenido acostumbrados, para dar paso ahora, a una en donde la imaginación, el respeto y la esperanza, se yergan como hilos tensores para recomponer el desfigurado rostro que la tristeza e incertidumbre han esbozado en quienes durante esta coyuntura perdieron un ser querido, o su trabajo, o han visto limitado de manera drástica la consolidación de su proyecto de vida bajo condiciones dignas.

De acuerdo con Rosero (2020):

La pandemia nos ha puesto de frente a algunas de las características más bárbaras del capitalismo. Ha develado las gigantescas inequidades, los extremos de pobreza y desigualdad; la devastación medioambiental; la economía que prioriza la especulación y el consumismo; las debilidades de los sistemas de salud; la corrupción y las redes de lumpen-acumulación; la fascistización y sus miserias. Ahí estaban desde antes. Lo que hizo la pandemia fue sacarlas a la luz. (p. 38) 
Ante el incierto panorama que se ofrece en términos económicos, políticos, sociales y ambientales, como producto del SARS-CoV-2, es claro que este ejercicio escritural no solo servirá para comunicar y aprender sobre el mundo social, sino también para contenernos emocionalmente. No es posible pensar sin silencio, y el cálido resguardo que brindan nuestros recuerdos y gustos, dentro de una época en donde todos se hallan agotados, como producto de la persecución del éxito individual y su más inmediata consecuencia, el olvido del otro, como afirma el filósofo contemporáneo Byung-Chul Han (2012).

Razón por la cual, resulta deseable que alguien hable. Que al menos una persona empeñe parte de su tiempo para visualizar desde la práctica del pensamiento crítico cómo serán posibles las relaciones con los otros en el futuro, ante la fatiga que presenta hoy el vivir y los preparativos en que se sumerge y proyecta la fiesta de la muerte social en las urbes, con sus énfasis en el amor sexualizado y su colindante ampliación del vacío existencial. Frente al cultivo del cuerpo con su galería de máquinas y productos gestionados por el mercado, al ansia de placer que nunca se agota, salvo cuando el cuerpo se deteriora, y la evidente incapacidad para aceptar la responsabilidad personal e invocar el futuro.

[...] La vida que se desarrolla en la ciudad, no es más que la teatralización de un proceso civilizatorio que en su momento estuvo colmado de buenas intenciones y promesas de gloria, pero que hoy constituye la causa de un buen número de situaciones negativas que afectan a sus agregados y visibiliza lo que ocurre en sus contornos. Esto toda vez que la ciudad moderna configura un espacio desde donde producir, relacionarse y vivir en el anonimato si se quiere, pero en cuya dinámica, lo que hay de fondo es una continua tensión entre los diferentes individuos que la habitan, frente a las demarcaciones socioespaciales, de tiempo y consumo, que se le imprimen a las personas y ciudadanos de dicho espacio público. (Segura-Gutiérrez, 2015, p. 73)

Sin duda, un panorama bastante narcisista y obstaculizador de la militancia política, que se complementa con las miradas tristes y sin color en el rostro de las gentes que deambulan por las calles de cada ciudad, como producto del uso de móviles inteligentes que multiplican la información, y a su vez orientan la autoexplotación del sujeto desde el dominio de su voluntad y la intención del mercado por controlarlos. "Cuando se quiere se puede" y "Si lo quieres, lo tienes" son algunos de los adagios populares que exponen la efectividad del discurso económico mercantil sobre la realidad actual. Ratificando así la premisa de Han (2012) que el exceso de libertad individual es exceso de capital. La libertad aumenta la exigencia de ser más competitivo.

Por tal motivo, todo se convierte en rutina, no hay espacio para conversar, negociar o soñar, y ante cualquier desacuerdo es mejor abandonar, aunque esto sea peor. Nos hemos ido acostumbrando a las soluciones inmediatas, en detrimento de conservar. Es una facilidad cuyo saldo social y político resulta negativo para todos, al deshumanizar a la persona, sobrecargar al ambiente en tanto proveedor de recursos para el mercado, y facilitar la corrupción de índole privada hacia el Estado. En ese sentido: 
La pregunta por la vida aparece entonces como un tema central, el modelo económico que hemos construido y que constituye nuestra cotidianidad no solo produce realidades caracterizadas por la desigualdad, el hambre, la injusticia y la guerra, sino que pone en riesgo la posibilidad misma de la existencia de la vida humana y la de miles de especies de todo tipo, en la medida en que avanza de manera voraz sobre territorios y recursos. (Pérez-Benavides, 2020, p. 26).

Ante la consigna actual de deshacerse de los problemas y obtener resultados instantáneos que mina la vida de facilismo, pensar en clave de futuro dentro del contexto de la pandemia significa percibir las similitudes que ofrecen los eventos. No con matices de positividad, sino de la aplicación de un ejercicio analítico y de solidaridad social, frente a la magnitud de los daños y pérdidas humanas causadas por el COVID-19 a nivel global. La preocupación por lo que vendrá no puede hacernos olvidar como afirma Saramago (1998) que:

Probablemente, solo en un mundo de ciegos serán las cosas lo que realmente son, dijo el médico, Y las personas, preguntó la chica de las gafas oscuras, Las personas también, nadie estará allí para verlas, Se me ocurre una idea, dijo el viejo de la venda negra, vamos a jugar para matar el tiempo, Cómo se puede jugar sin ver lo que se juega, preguntó la mujer del primer ciego, No va a ser exactamente un juego, se trata de que cada uno de nosotros diga exactamente lo que estaba viendo en el momento en que se quedó ciego. (p. 149)

Cuestión que exige templanza y pericia mental, si la intención es generar visión y compromiso, dentro de las actuales coordenadas políticas, sociales y económicas, que el neoliberalismo y COVID-19 han delineado para los próximos años, con la exacerbación del consumo, la delegación por parte de las empresas de la publicidad en sus clientesconsumidores, y la gestión del coronavirus por parte de los Estados bajo elementos biopolíticos que afectan el cuerpo social y penetran en el cuerpo individual, mostrando cómo el alcance de la inmunidad se encuentra atravesada por criterios políticos y económicos que resquebrajan la idea de una igualdad cívica. Razón para compartir con Hernández-Álvarez y Restrepo-Botero (2020), su metáfora:

sí lo hizo el COVID 19, parece que también nos tocó mutar a nosotros, mutar hacia una relación respetuosa, cuidadora de toda forma de vida, basada en el consumo vital, los mercados internos, de ciclos cortos, con más intercambio y menos acumulación.

Bajo la lógica del aislamiento obligatorio se aumentan las vulnerabilidades de los más débiles, además de dejarlos a la deriva dentro de un escenario cargado de miedo, desolación y estigma social, mientras que con la aplicación de tecnologías Big Data, la libertad es manejada y logra individualizar a los portadores y enfermos por COVID-19. Situación que describe cómo somos administrados, y nuestra existencia cobra visibilidad dado el apetito informativo, que lleva a generar datos por ejemplo vía suscripción que a su vez son ubicados dentro de una colección de otros datos, perfectamente articulados en sistemas de información, que viajan sin límites y adquieren un alto valor monetario en el ámbito 
comercial, publicitario y de ocio. Ratificando de esta manera, el determinismo tecnológico y relevancia en la configuración estructural y política del ser humano.

A manera de ejemplo:

[...] y para el caso del big data y de sus supuestos beneficios, no se puede obviar sin más que los problemas sociales que pretende resolver están arraigados a las propias estructuras de poder que, en gran medida, los configuran. En ese mismo sentido, el desarrollo de nuevas formas de tecnología, como todas aquellas que acompañan a los procesos de inteligencia artificial, suelen ir acompañadas desde su nacimiento por problemas graves desde el ámbito sociopolítico, tales como la reproducción de patrones de prejuicio social o la injerencia política ilegítima en los ámbitos de la privacidad de los individuos, agravando nuevos (o viejos) problemas de nuestro entorno físico. (Ramos-Martín, 2020, p. 62)

Esto, sin dejar de señalar que parte de la situación actual que vive el mundo, tiene como origen la exponencial destrucción ambiental provocada por la industrialización de diferentes regiones del mundo. Además del aumento de la tolerancia de las personas al control cibernético corporativo y estatal, que lleva a que la subjetividad ahora se halle enmascarada como condición para poder sobrevivir y dar el grito individual de supervivencia al interior de una casa, un apartamento, o la habitación en la cual se hallan encerradas y desde donde ahora hacen teletrabajo, pero además se descolectivizan y telecontrolan a sí mismos. Según Gómez (2020):

[...] a partir de la pandemia del COVID-19 se producirá en el mundo entero una especie de dictadura policiva global, alentada por 'supuestos' del capitalismo neoliberal (neoconservador) o "salvaje", tales como el crecimiento económico y el desarrollo sostenible, supuestamente necesarios para alcanzar la equidad material. Las armas principales para el establecimiento de dicho nuevo orden ya no serán las de la guerra de trincheras, ni la guerra química, sino las del control del orden público, de la sujeción y salud de los cuerpos y del crecimiento económico a través de medios nano-bio-info-cogno-tecnológicos. (p. 72)

La pandemia de la COVID-19 ha permitido comprender cómo la tecnología se convierte en un elemento de prevención y control biopolítico que lleva a identificar cambios en la significación de la vida y priorización de la economía sobre otras dimensiones sociales y culturales. A diferencia de otras pandemias históricas, la COVID-19 llegó a un mundo interconectado, globalizado y con altos niveles de urbanización, que posibilita y acerca la inequidad y pobreza de un buen número de poblaciones, pero también mostrando cómo los modelos de gestión pública instituidos, en buen número se hallan descontextualizados de la realidad local a la cual aspiran intervenir y ofrecer soluciones focalizadas.

La creación de políticas públicas puede pensarse, entonces, como un espacio de intervención de los científicos sociales, con la participación de la sociedad civil y de los territorios más afectados por las desigualdades preexistentes y por los efectos de la COVID-19, hacia una justicia territorial. La disyuntiva de morir de hambre o morir de Coronavirus emerge en las representaciones y la 
Segura-Gutiérrez y Vásquez-Ávila

desesperanza en la vida cotidiana de poblaciones que han sido excluidas de los sistemas de educación, salud y trabajo, como consecuencia del ciclo: menos educación -menos ingresosmenos oportunidades. (Cabra-Torres, 2020, p. 96)

Razón esta para que desde las ciencias sociales se deba impactar en la vida pública con tenacidad. El contexto esbozado por la crisis sanitaria ha revelado sin cortapisas la brecha de desigualdad económica y de poder en que se halla el mundo y a la cual solo queda resistir y emanciparnos cognitivamente, dando así señales que las ciencias sociales siguen estando vivas y no bajo la sombra de la economía global -capitalismo- y el autoritarismo emergente de los Estados.

En medio de la pandemia habrá seguramente quien se afane en la búsqueda de un culpable, ya sea en la piel del chivo expiatorio o en el papel de villano. Se trata, seguramente, de un gesto inconsciente para ponerse a salvo: encontrar a quién atribuir la culpa tranquiliza porque desplaza la responsabilidad. Sin embargo, más que empeñarnos en desenmascarar a un sujeto, resulta más oportuno identificar una forma de subjetivación, es decir, interrogarnos acerca del modo de vida capaz de desatar estragos tan dramáticos como los que hoy nos atraviesan la existencia. Se trata, sin duda, de una pregunta que ni nos salva ni nos reconforta $y$, mucho menos, nos ofrece un afuera. Básicamente porque ese modo de vida es el nuestro. (Lara, 2020)

La desigualdad social, acrecentada por el impacto COVID-19 ahora se revela bajo la tripleta salud (dificultades en el acceso y disponibilidad de medicamentos y especialistas), educación (ausencia de recursos por parte de las familias para garantizar la permanencia de los escolares) e ingresos (formalidad del empleo), dando lugar a que por ejemplo la clase media, conformada por prestadores de servicios, propietarios de negocios pequeños, no se encuentren focalizados dentro de los paquetes de ayuda, "su mayor fragilidad es estar en la mitad entre la asistencia social y la imposibilidad de retomar sus labores" (Guevara y La Rotta, 2020).

Situación que augura la conflictividad social y movilización como mecanismo para establecer en la etapa postCOVID-19, una agenda pública-colectiva de las situacionesproblema generadas por la economía global, y en la cual los involucrados se reconozcan como parte del problema y proyección de las soluciones, ante la corresponsabilidad que les asiste por las divisiones del trabajo y producción de bienes y servicios, que ha zanjado el capitalismo y que requieren de la transformación de ciertos comportamientos depredadores hasta ahora consentidos.

La crisis de la pandemia en Colombia acarrea unas problemáticas aún mayores que agravan la situación y que no se pueden pasar por alto. No solo tenemos un número mucho más elevado de habitantes por ciudad, sino que una gran parte de la población trabaja al día para comer y pagar un lugar donde vivir, una gran parte de la población vive de trabajos informales, una gran parte de la población habita en condiciones de pobreza o de pobreza absoluta. (Londoño-Venegas, 2020, pp. 22-23) 
Por ello, estas hojas y hablas son la oportunidad para alzar la voz e intentar cambiar nuestras prácticas sociales y estilos de vida hacía unos más solidarios y de cooperación social. La vigilancia digital, ya lo expone Han (2012), fortalecerá el modelo neoliberal y provocará el aislamiento e individualización. Dando lugar a una ética del "sálvese quien pueda", y en donde los intereses económicos empresariales y enclaves políticos aprovecharán la oportunidad para implantar en todo el globo el modo de vida imperial ya "ampliamente aceptado, amarrado institucionalmente y profundamente arraigado en las prácticas cotidianas de la gente; un modo de vida relacionado con determinadas ideas sobre el progreso" (Brand y Wissen, 2014, p. 5).

Es decir, de un artificio prefigurado por quienes detentan el poder económico y político, y que ante la persistencia de la epidemia afilará sus garras para sujetar a las ciencias sociales en su papel de disciplinas favorecedoras del cuidado, pero también a los sujetos individuales y sociales frente a un posible cambio de prácticas o prioridades y ante el cual el Estado no podrá oponer gran resistencia, él mismo ha generado las condiciones para que el futuro se visualice desde el "vivir el presente" y sin tintes de apego local. Dando lugar, a una convivencia en donde lo único posible de compartir es la normalizada vulnerabilidad por la que estamos atravesando, y en donde ninguno se anima a participar dado que ve a los otros como una amenaza catastrófica para su propia vida. Esperemos entonces, que no sea tan lejano, volver a ver sin riesgos el sol de los venados.

\section{Conclusiones}

En este ensayo se ha argumentado que las ciencias sociales no solo son un conjunto de disciplinas que se resisten a la instrumentalización por parte del capitalismo neoliberal con sus organizaciones empresariales y unidades políticoadministrativas, sino un campo productivo de saber, desde el cual se intenta generar respuestas reales ante el momento coyuntural de emergencia sanitaria. Esto en virtud a que la complejidad misma de su conformación le permite ser una herramienta clave en la comprensión de situaciones como el uso de tecnología en la subjetividad, activismo político digital, videovigilancia, segregación espacial e incluso las prácticas de cuidado y autocuidado a tener en cuenta para reducir los contagios a causa del Coronavirus, y que debieran ser consideradas por parte de los líderes mundiales.

El Virus SARS-CoV-2 (COVID-19) irrumpió de manera inaudita en el escenario mundial, generando acciones de desobediencia, enclaustramiento y nuevas formas de empleabilidad, que sin duda deben ser analizadas en sus impactos individuales, sociales, económicos, culturales, más inmediatos y de largo plazo, pero también reafirmando cómo el mundo globalizado hoy parte desde nuestro propio hogar, como producto de la interacción constante con las tecnologías de la información y comunicación, que nos enlazan 
con lo familiar, laboral, sexual, y además convierte en consumidores sin miedo dentro de un contexto de marcada fragilidad como resultado del diseño y ejecución de estrategias de gestión biopolítica a escala global.

Situación que hace posible pensar desde las ciencias sociales representadas en cada uno de los autores de este texto (administración pública, economía y administración de empresas), cómo a la sociedad actual le urge rescatar el diálogo interdisciplinar propio de este campo de saber, a fin de comprender el funcionamiento del motor que impulsa la ejecución de prácticas depredadoras del ambiente, y en él, identificar los canales por medio de los cuales transitan sin obstáculo los flujos comerciales y de mercado, y que hoy han favorecido la instauración de las tecnologías de control y vigilancia, que hay que abordar sin dilaciones en torno a sus alcances y limitaciones en el presente y futuro venidero. Un tiempo, que imaginamos con mayores rasgos de individualidad, abandono y falta de privilegios para muchos, pero en donde lo común a todos serán las fantasías digitalizadas.

El COVID-19 dejó en la memoria colectiva, el ocultamiento y la aniquilación solitaria de un mundo hiperconectado pero en cuyos rostros de buena parte de quienes lo integran solo se percibe silencio, sonrisas moderadas y, por qué no, un genuino deseo de gritar estoy vivo y quiero ser libre, como intentamos hacer al escribir este ensayo. Las ciencias sociales en tiempos de crisis, sin duda nos llevan a reafirmar nuestra condición de sujetos gregarios, con todo lo que ello implica.

\section{Referencias bibliográficas}

Álvarez-Gallego, A. (2014). El surgimiento de las ciencias sociales y el olvido de una pedagógica política. Nómadas, (41), 45-61. Recuperado de http://www.scielo.org.co/pdf/noma/n41/n41a04.pdf.

Barba-Jacob, P. (2011). Canción de la vida profunda. Antología. Bogotá, Colombia: Universidad Externado de Colombia

Barreneche-Jurado, C., Cabra-Torres, F., Hernández-García, I., Niño-Bernal, R., RodríguezRuiz, J. A., y Marciales-Vivas, G.P. (2018). Las ciencias sociales y humanas en la actual sociedad del conocimiento: escenarios de indagación inter y transdisciplinar. Bogotá, Colombia: Pontificia Universidad Javeriana.

Brand, U., y Wissen, M. (2014). Crisis socioecológica y modo de vida imperial. Crisis y continuidad de las relaciones sociedad-naturaleza en el capitalismo. Saskab. Revista de Discusiones Filosóficas Desde Acá, (7), 1-27. Recuperado de http://www.ideazinstitute.com/sp/CUADERNO7/C71.pdf.

Brown, R. H. (2002). La ciencia social y la búsqueda de una sociedad justa. Revista de Estudios Sociales, (13), 27-35. doi: 10.7440/res13.2002.02.

Busso, A. (2020). Pandemia y orden internacional: incertidumbre entre lo viejo que no quiere morir y lo nuevo que no termina de nacer. En A. Busso (Coord.), Relaciones 
internacionales en tiempos de pandemia (pp. 6-22). Argentina: Universidad Nacional de Rosario. Recuperado de https:/ / rephip.unr.edu.ar/xmlui/handle/2133/18304.

Cabra-Torres, F. (2020). Las incertidumbres de la vida post Covid y la construcción de futuro. En A. C. Pérez-Benavides (Coord), Pensamientos virales: las ciencias sociales y humanas en tiempos de crisis (pp.87-103). Bogotá, Colombia: Pontifica Universidad Javeriana- Sensolab microediciones. Recuperado de https:/ / drive.google.com/file/d/1ydJi11b1XvsYRWNwobceXtHPxPX6NQ5-/view.

Carli, S. (2014). Las ciencias sociales en argentina: itinerarios intelectuales, disciplinas académicas y pasiones políticas. Nómadas, (41), 63-77. Recuperado de http://www.scielo.org.co/pdf/noma/n41/n41a05.pdf.

Catanzaro, G. (2019). ¿Cómo leer el neoliberalismo contemporáneo? Algunos desafíos de la crítica ideológica del momento actual. Argumentos. Revista de Crítica Social, (21), 43-70. https:/ / publicaciones.sociales.uba.ar/index.php/argumentos/article/view/ 4963.

Center for Systems Science and Engineering [CSSE]. (2021). Tracking COVID-19. Recuperado https:/ / www.arcgis.com/apps/opsdashboard/index.html\#/bda7594740fd40299423 467b48e9ecf6.

Comisión Económica para América Latina y el Caribe [CEPAL]. (2020). Balance Preliminar de las Economías de América Latina y el Caribe. Santiago: CEPAL. Recuperado de https://www.cepal.org/sites/default/files/presentation/files/version_final_panor ama_social_para_sala_prebisch-403-2021.pdf.

Covarrubias-Villa, F., y Cruz-Navarro, M. (2019). La apropiación paisajística del territorio: una disputa epistemológica. Cinta de Moebio. Revista de Epistemología de Ciencias Sociales, (64), 82-98. Recuperado de https:/ / cintademoebio.uchile.cl/index.php/CDM/article/view/52776/57939.

Devakumar, D., Shannon, G., Bhopal, S. S., \& Abubakar, I. (2020). Racism and discrimination in COVID-19 responses. The Lancet, 395(10231), 1194. doi: 10.1016/S01406736(20)30792-3.

Erlbruch, W. (2007). El pato y la muerte. México: Océano.

Feige, K. (Productor), \& Branagh, K. M. (Director). (2011). Thor. [Película]. Estados Unidos: Marvel Studios.

Fernández-Esquinas, M. (2020). Sociología y Ciencias Sociales en tiempos de crisis pandémica. Revista de Sociología de la Educación-RASE, 13 (2), 105-113. doi. 10.7203/RASE.13.2.17113.

Flores-Osorio, J. M., Huerta-Charles, L., y Bravo, O. A. (Eds.). (2020). Las ciencias sociales: Al otro lado del discurso neoliberal. Colombia y México: Universidad de Tijuana y Universidad Icesi. doi: 10.18046/EUI/ee.5.2020.

Fuchs, M., \& Potter, J. (2020). Societal experiences of lesbian, gay, bisexual, and transgender people. In M. Legato (Ed.), The Molecular Biology and Clinical Features of Genomic Sex, Gender Identity and Sexual Behavior (pp. 243-275). Reino Unido: Academic Press. Recuperado de 10.1016/B978-0-12815968-2.00015-3. 
Gómez, J. D. (2020). Pandemia: ¿crisis u oportunidad? En A. C. Pérez-Benavides (Coord), Pensamientos virales: las ciencias sociales y humanas en tiempos de crisis (pp. 71-84). Bogotá, Colombia: Pontifica Universidad Javeriana. Sensolab microediciones. Recuperado de https://drive.google.com/file/d/1ydJi11b1XvsYRWNwobceXtHPxPX6NQ5-/view.

Guevara, D., y La Rotta, S. (18 de abril de 2020). El baile de los que sobran: la población sándwich en la crisis del COVID-19. El Espectador. Recuperado de https:/ / www.elespectador.com/coronavirus/elbaile-de-los-que-sobran-lapoblacion-sandwich-en-la-crisis-delcovid-19-articulo-915208.

Han, B. C (2012). La sociedad del cansancio. España: Herder.

Hernández-Álvarez, M., y Restrepo-Botero, D. (20 de mayo de 2020). COVID-19 y salud: mutar para vivir. UN Periódico Digital. Recuperado de https:/ / unperiodico.unal.edu.co/pages/\%20detail/covid-19-y-salud-mutar-paravivir/.

Isaza-Villamizar, E., González-Casabianca, F., Herrera, S., Rodríguez-Barraquer, T., Ángel, A., Corredor, V... Feged-Rivadeneira, A. (2020). Políticas públicas, grandes datos, teoría de redes y COVID-19. Desafíos, 32(2), 1-19. doi: 10.12804/revistas.urosario.edu.co/desafios/a.9205.

Kissinger, H. A. (3 de abril de 2020). The Coronavirus Pandemic Will Forever Alter the World Order. The Wall Street Journal. Recuperado de https://www.wsj.com/articles/the-coronavirus-pandemic-will-forever-alter-theworld-order-11585953005.

La Casa Azul. (2016). Podría ser peor [Canción]. La gran esfera. Elefant Records.

La Casa Azul. (2018). Nuca nadie pudo volar [Canción]. La gran esfera. Elefant Records.

Lara, Á. L. (29 de marzo de 2020). Causalidad de la pandemia, cualidad de la catástrofe. elDiario.es. Recuperado de https://www.eldiario.es/interferencias/Causalidadpandemiacualidad-catastrofe_6_1010758925.html.

Londoño-Venegas, S. (2020). Un recuerdo recompuesto: entre realidad y memoria. En J. J. Fernández-Dusso, X. Castro-Sardi, D. Cagüeñas-Rozo, D. P. Quintero, y R. Silva-Vega. (Comps.). Ensayos sobre la pandemia (pp. 13-24). Colombia: Universidad Icesi. https:/ / repository.icesi.edu.co/biblioteca_digital/bitstream/10906/86919/6/londo no_ensayos_pandemia_2020.pdf.

Luhmann, N. (2007). La sociedad de la sociedad. España: Herder.

Martz-Fernández, F. (2017). Transición política: un mapeo teórico en medio de la dispersión bibliográfica. Cuestiones Políticas, 33(59), 58-84.

Mazza, M., Marano, G., Lai, C., Janiri, L., \& Sani, G. (2020). Danger in danger: Interpersonal violence during COVID-19 quarantine. Psychiatry research, 289, 113046. doi: 10.1016/j.psychres.2020.113046.

Pérez-Benavides, A. C. (2020). Observar el presente: una invitación a mirarnos como sociedad en el espejo de la pandemia. En A. C. Pérez-Benavides (Coord.), Pensamientos virales: las ciencias sociales y humanas en tiempos de crisis (pp. 25-36). Bogotá, Colombia: 
Pontifica Universidad Javeriana- Sensolab microediciones. Recuperado de https:/ / drive.google.com/file/d/1ydJi11b1XvsYRWNwobceXtHPxPX6NQ5-/view.

Pignatta, E. (2020). Política internacional latinoamericana, cambios de ciclo y agenda regional en la coyuntura de pandemia. En A. Busso (Coord.), Relaciones internacionales en tiempos de pandemia (pp. 170-177). Argentina: Universidad Nacional de Rosario. https:/ / rephip.unr.edu.ar/xmlui/handle/2133/18304.

Ramos-Martín, J. (2020). La distopía perfecta: datificación soberanía informacional y pandemia. En A. C. Pérez-Benavides (Coord), Pensamientos virales: las ciencias sociales y humanas en tiempos de crisis (pp. 59-69). Bogotá, Colombia: Pontifica Universidad Javeriana- Sensolab microediciones. Recuperado de https:/ / drive.google.com/file/d/1ydJi11b1XvsYRWNwobceXtHPxPX6NQ5-/view. Rodríguez-Basail, A. (Coord.). (2019). Academias asediadas: convicciones y conveniencias ante la precarización. México: CLACSO - Consejo Latinoamericano de Ciencias Sociales, UNICACH - Universidad de Ciencias y Artes de Chiapas y CESMECA - Centro de Estudios Superiores de México y Centroamérica. Recuperado de http:/ / biblioteca.clacso.edu.ar/clacso/se/20200210034630/Academiasasediadas.pdf.

Rosero, A. (2020). Coronavirus y crisis civilizatoria: La pseudo-"normalidad" en el capitalismo de la globalización. Boletín Académico Sociología y Política Hoy, (4), 24-41. Recuperado de https:/ / revistadigital.uce.edu.ec/index.php/hoy/article/view/2576/2898.

Roy, A. (13 de abril de 2020). La pandemia es un portal. La jornada. Recuperado de https://www.jornada.com.mx/ultimas/mundo/2020/04/13/la-pandemia-es-unportal-9285.html.

Ruiz, C. y Caviedes, S. (2020). Estructura y conflicto social en la crisis del neoliberalismo avanzado en Chile. Espacio abierto. Cuaderno Venezolano de Sociología, 29(1), 86-101. Recuperado de https:/ / bit.ly/3gkcIFN.

Saramago, J. (1998). Ensayo sobre la ceguera. México: Alfaguara.

Segura-Gutiérrez, J. M. (2015). Ciudad: ¿Máscara civilizatoria? Cooperativismo E Desarrollo, 23(106), 67-73. Recuperado de https:/ / dialnet.unirioja.es/ servlet/articulo?codigo=5243260.

Smouts, M. C. (1997). La région comme nouvelle communauté imaginaire. En P. Le Gales \& C. Lequesne (Eds.), Les paradoxes de la région en Europe (pp.37-45). Francia: La Découverte. 


\section{OTROS ARTÍCULOS DE PROSPECTIVA No. 33}

\section{EDITORIAL}

El Paro Nacional en Colombia 2021: explosión social entre dinámicas estructurales y de coyuntura. Relevancia de la acción política y del diálogo en su desarrollo y transformación Adolfo Adrián Álvarez-Rodríguez

\section{ARTÍCULOS}

Organizaciones sociales de pobladores y prácticas de resistencia en contexto de pandemia COVID-19 en Chile

Patricia Castañeda-Meneses

Entre el aislamiento y las brechas digitales: sistematización de experiencia de acompañamiento socioemocional en personas mayores de Temuco, Chile, en tiempos de COVID-19

G. Bernarda Aedo-Neira

Percepción de apoyo social y calidad de vida: la visión de personas mayores chilenas en el contexto de pandemia durante el 2020

Claudia Elena Quiroga-Sanzana

Gabriela Rocío Parra-Monje

Camila Julia Moyano-Sepúlveda

Marco Alejandro Díaz-Bravo

A propósito del qué, cómo y para qué investigar en el campo de la justicia juvenil: La trastienda de un proceso de investigación en Rosario, Argentina Karina De Bella

Proyección social: reflexión sobre una experiencia virtual con adolescentes en época de pandemia en Sucre y Bolivar, Colombia

Claudia Yaneth Martínez-Mina
La intervención social mediante proyectos comunitarios en modalidad virtual en Mérida, México. Una perspectiva desde el Trabajo Social Claudia Isabel Tzec-Puch Amairani Aracelly Ceh-Alvarado Yanet Guadalupe González-Canul

Resignificación de los vínculos Sociales durante la pandemia de COVID-19: narrativas de personas que convergen en Conjuntos residenciales en Bogotá, Colombia

Andrea Marcela Reyes-García

Laura Daniela Molina-Ortiz

La paradoja de la familia doblemente recluida: clínica de una pandemia en Colombia

Norman Darío Moreno-Carmona

Juan José Cleves-Valencia

Ciencias sociales, mundo y pandemia: por un futuro posible

José Miguel Segura-Gutiérrez

Lina Paola Vásquez-Ávila

¿Qué es Trabajo Social? Los primeros vínculos de los estudiantes con la profesión: experiencias de Argentina, Brasil, Paraguay y Uruguay

Silvia Orieta Rivero-Rodríguez

Leonel Del Prado

Nidia Graciela Battilana-Amarilla

Rosilaine Coradini-Guilherme

Intervención profesional de trabajadores sociales de la universidad del Quindio, Colombia. Asuntos epistemológicos, metodológicos y ético-políticos

Ana María Gil-Ríos 
Reflexiones sobre la intervención social en lo rural: experiencias en el Magdalena Medio, Colombia

Claudia Milena Quijano-Mejía

Johana Linares-García

Construcción de rutas de atención integral a la convivencia escolar en Cali, Colombia: sistematización de la experiencia

Leidy Johana Prado-Montaño

Luz Helena López-Rodríguez

Alejandra Gutiérrez-Cárdenas

Experiencia del proceso de intervención familiar de los actores participantes en la Escuela para Familias del ICBF-Jamundí, Colombia Katherin Viviana Silva-Minotta

María José Forero-Izquierdo

Jimena del Pilar Jaramillo-Jaramillo

\section{RESEÑAS DE LIBROS}

Alerta global: políticas, movimientos sociales y futuros en disputa en tiempos de pandemia Jairo Crispín

El neoliberalismo como teología política. Habermas, Foucault, Dardot, Laval y la historia del capitalismo contemporáneo

José Francisco Desentis-Torres

La Reconceptualización del Trabajo Social en Colombia: Análisis histórico-crítico de las décadas de 1960-1970

Juan Pablo Sierra-Tapiro

ARTISTA INVITADO

Juan Camilo González

Prospectiva

\section{PROSPECTIVA}

Revista de Trabajo Social e Intervención Social

No. 33 • ene.-jun. 2022

e-ISSN: 2389-993X • Universidad del Valle 